\title{
Wire-Guided Localization Biopsy for Non-Palpable Suspicious Breast Lesions
}

\author{
Tamer A. El-Bakary ${ }^{1}$, S. Abdelazim¹, Bashdar Ramadan Mawolood², \\ Mohamed S. Hashish ${ }^{*}$ \\ ${ }^{1}$ Department of surgery, Tanta University Hospital, Tanta, Egypt \\ ${ }^{2}$ Department of radiology, Hamad Medical Corporation, Doha, Qatar \\ Email: dr mohamed hashish@yahoo.com
}

Received 18 May 2015; accepted 6 July 2015; published 9 July 2015

Copyright () 2015 by authors and Scientific Research Publishing Inc.

This work is licensed under the Creative Commons Attribution International License (CC BY). http://creativecommons.org/licenses/by/4.0/

(c) $\underset{\mathrm{EY}}{\mathrm{EY}}$ Open Access

\section{Abstract}

Background: About 25\% - 35\% of breast cancers are non-palpable at the time of diagnosis. Wire guided localization (WGL) had been considered as the standard technique for many years for excision of theses breast lesions. The aim of this study is to assess the efficacy of WGL biopsy in the management of non-palpable suspicious breast masses. Patients \& Methods: This retrospective study concerned thirty female patients who were presented by non-palpable breast lesions as proved by mammography and complimentary ultrasonography between February 2013 and September 2014. According to BIRADS classification system, all the lesions were BIRADS III, IV and V. However, BIRADS I and II lesions proved to be benign were excluded from this study. The patients were submitted to WGL under local anesthesia. Then, they were shifted to the operating theatre, where they underwent WGL biopsy. The removed specimens were sent for radiological confirmation of complete excision. Then, it was sent for histopathological examination. Results: The mean age was 52.63 years. Eighteen patients $(60 \%)$ were asymptomatic, $7(23.3 \%)$ patients were with breast pain, and 5 patients (16.7\%) had nipple discharge. Ten lesions (33.3\%) were BIRADS III, 17 lesions (56.7\%) were BIRADS IV, and 3 lesions (10\%) were BIRADS V. The WGL was done by mammography in 19 patients (63.3\%) and under ultrasonographic guidance in 11 patients (36.7\%). No post-operative complications were reported. The mean tumor size was $11.23 \mathrm{~mm}$ and the mean safety margin of excision was $6.7 \mathrm{~mm}$. IDC was found in $56.7 \%$ or cases, DCIS in $30 \%$, and ILC in $13.3 \%$ of cases. $40 \%$ of the lesions were of grade I, $30 \%$ were of grade II, and $30 \%$ were of grade III. There were positive resection margins in 11 patients $(36.7 \%)$. Conclusion: WGL biopsy is a safe and reliable surgical technique for management of non-palpable suspicious breast lesions. Special care should be paid for proper margin excision. However, WGL biopsy is technically demanding and needs learning curve for both the surgeon and the radiologist.

${ }^{*}$ Corresponding author. 


\section{Keywords}

\section{WGL, Non Palpable, Breast Cancer \& Excision}

\section{Introduction}

Breast cancer is the commonest cancer among females. About $25 \%-35 \%$ of breast cancers are non-palpable at the time of diagnosis [1]. The emergence of breast screening programs and novel radiological techniques like breast MRI have resulted in early detection of many non-palpable breast lesions [2].

These lesions need special way of localization to help for intra-operative identification and excision [1]. Wire-guided localization (WGL) has been the standard technique used for many years for localization of nonpalpable breast lesions using either ultrasound or mammography preoperative [3]. A thin and hooked wire is inserted into the lesion, and the surgeon uses the wire and standard imaging to identify and remove the lesion [2] [4].

This enables the surgeon to have accurate excision with unnecessary removal of large amount of normal breast tissue especially in benign lesions [4]. However, WGL has its own problems e.g. wire dislocation, patient discomfort, and rarely pneumothorax that have been reported in some cases [5]. Also, inadequate resection may expose the patient to a second surgery [6].

We designed this study to assess the effectiveness of WGL in achieving proper surgical excision of nonpalpable suspicious breast lesions with adequate safety margins.

\section{Patients and Methods}

Between February 2013 and September 2014, thirty female patients were enrolled in this study in Department of surgery in Hamad Medical Corporation, Doha, Qatar, (Ethical approval No. 33456700) and Department of surgery, Tanta University Hospital, Tanta, Egypt (Research approval No. 000045346) Some of them were asymptomatic and they came for screening mammography. Some had non specific breast complaints (e.g. breast pain \& nipple discharge). Clinical examination of all the patients did not show any palpable breast mass. All the patients were submitted to bilateral mammography and complementary ultrasonography that showed the presence of non-palpable breast mass. Informed consent was obtained from all our patients

According to Breast-Imaging Reporting \& Data System (BIRADS), these non-palpable masses were BIRADS III, IV \& V. Exclusion criteria included benign looking masses (BIRADS I \& II) and lesions that proved to be benign by histopathological examination. Informed consent was taken from all the patients. In the same day of surgery, A 20-gauge hooked wire was inserted into the non-palpable breast mass under local anesthesia with mammography guidance or ultrasound guidance if the lesion could be seen by ultrasound Figure 1 and Figure 2.

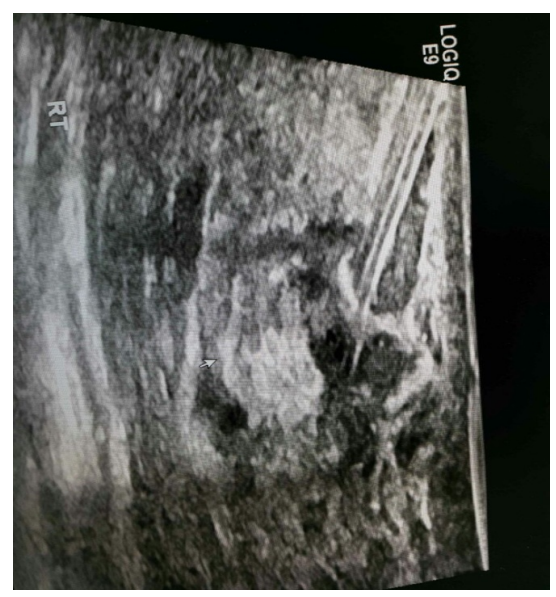

Figure 1. Mamography with wire guided localized in mass (arrow) in Rt breast. 


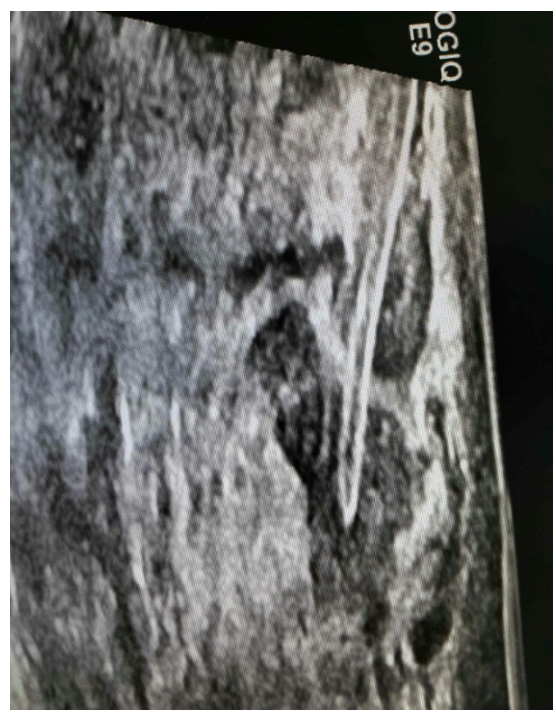

Figure 2. Wire 20 gaug was inserted in breast mass.

After proper localization, the wire was tapped tightly to the skin to prevent dislocation and the patient was shifted to the operating theatre where she was submitted to WGL biopsy under general anesthesia. Our preferred incision was curvilinear incision centered over the entrance of the wire through the skin.

The surgeon follow the wire through the breast tissue down to the mass with meticulous excision was done that ensure proper resection of the mass with adequate safety margins. The margins of the removed specimen was marked by sutures and sent to radiology department for further confirmation that proper excision of the whole mass was accomplished. The breast tissue was closed in 2 layers by absorbable sutures with no drains. The skin was closed by absorbable monofilament sutures. The removed specimen was then sent for histopathological examination that includes proper assessment of the margins of excision. The minimal accepted safety margins were $5 \mathrm{~mm}$. Re-excision was required if any margin was less than $5 \mathrm{~mm}$.

A student t-test was used to compare differences between positive and Negative margins patients. Associations of categorical variables with Positive and Negative margins patients were assessed using chi-square test. When expected cell frequency was inadequate, a Fischer Exact test was used instead. A two-sided P value of $\leq 0.05$ was considered to be statistically significant. All statistical analyses were done using statistical packages SPSS 19.0 (SPSS Inc. Chicago, IL).

\section{Results}

The age of the patients ranged between $42 \& 69$ years with a mean of 52.63 years. Eighteen patients $(60 \%)$ were asymptomatic, 7 (23.3\%) patients had breast pain, and 5 patients (16.7\%) had nipple discharge. Mammography was done in all the patients. It showed non-palpable lesion in the upper outer quadrant in 12 patients $(40 \%)$, in the lower outer quadrant in 6 patients (20\%), in the upper inner quadrant in 5 patients $(16.7 \%), \&$ in the lower inner quadrant in 7 patients (23.3\%). According to BIRADS classification, 10 lesions were BIRADS III (33.3\%), 17 lesions (56.7\%) were BIRADS IV, \& 3 lesions (10\%) were BIRADS V. The WGL was done by mammography in 19 patients (63.3\%) and under ultrasonographic guidance in 11 patients (36.7\%). WGL biopsy was successfully done in all the cases as proved by radiological imaging of the removed specimens i.e. no wire migration or dislocation was reported. No post-operative complications were encountered. The histopathological outcome of the excised lesions was shown in Table 1.

The tumor size ranged between $2 \mathrm{~mm}$ and $25 \mathrm{~mm}$ with a mean of $11.23 \mathrm{~mm}$. The mean safety margin of excision was $6.7 \mathrm{~mm}$. There were positive margins in 11 patients $(36.7 \%)$ who required re-excision. Table 2 shows the relation between different prognostic factors and the margins status. There was no significant difference regarding prognostic factor between patients with positive safety margins with those of negative margins except regarding the histopathological grades there was significant difference between 2 groups. 
Table 1. Histopathological outcome.

\begin{tabular}{cc}
\hline Histopathology & No. (\%) \\
\hline Invasive Ductal Carcinoma (IDC) & $17(56.7)$ \\
Ductal Carcinoma In-situ (DCIS) & $9(30)$ \\
Invasive Lobular Carcinoma (ILC) & $4(13.3)$ \\
Histopatholgical Grade & No. $(\%)$ \\
\hline Grade I & $12(40)$ \\
Grade II & $9(30)$ \\
Grade III & $9(30)$ \\
\hline Hormonal Receptor Status & No. (\%) \\
\hline Positive & $22(73.3)$ \\
Negative & $8(26.7)$ \\
\hline
\end{tabular}

Table 2. Relation between different prognostic factors and excision margins.

\begin{tabular}{|c|c|c|c|}
\hline Prognostic Factor & Negative Margins $($ No. $=19)$ & Positive Margins (No. = 11) & p Value \\
\hline Age & Mean $=55.37$ & Mean $=47.9$ & 0.466 \\
\hline Tumor size (mm) & Mean $=11.32$ & Mean $=11.09$ & 0.96 \\
\hline \multicolumn{4}{|l|}{ Histopathology: } \\
\hline IDC $($ No. $=17)$ & 11 & 6 & 0.23 \\
\hline DCIS (No. $=9$ ) & 6 & 3 & 0.317 \\
\hline ILC (No.=4) & 2 & 2 & 1 \\
\hline \multicolumn{4}{|l|}{ Grade: } \\
\hline $\mathrm{I}($ No. $=12)$ & 9 & 3 & $0.03^{*}$ \\
\hline II (No. = 9) & 7 & 2 & $0.046^{*}$ \\
\hline III (No. = 9) & 3 & 6 & 0.317 \\
\hline \multicolumn{4}{|l|}{ BIRADS: } \\
\hline III (No. = 10) & 7 & 3 & 0.2 \\
\hline IV $($ No. $=17)$ & 11 & 6 & 0.23 \\
\hline $\mathrm{V}($ No. $=3)$ & 1 & 2 & 0.5 \\
\hline \multicolumn{4}{|c|}{ Hormonal receptor status: } \\
\hline Positive $($ No. $=22)$ & 14 & 8 & 0.19 \\
\hline Negative $($ No. $=8)$ & 5 & 3 & 0.48 \\
\hline
\end{tabular}

${ }^{*} \mathrm{P}$ value of $\leq 0.05$.

\section{Discussion}

The increasing awareness about breast cancer and widespread use of screening mammography nowadays increased the incidence of detection of suspicious non-palpable breast lesions [1]. Many of these lesions were asymptomatic as shown in our study where $60 \%$ of the patients had no symptoms and the breast mass was shown only on mammography. These masses have to be removed with adequate safety margins and with good cosmetic outcome [7]. Wire guided localization followed by surgical excision of the non-palpable breast mass was first described by Frank et al. [8] in 1976. In spite of developing many other radiological localization techniques e.g. radio-guided localization, sentinel node and occult lesion localization, and radio-active seed localization, WGL is still considered as the gold standard technique for excision of non-palpable suspicious breast masses [9].

In our study, WGL was done under mammograghic guidance in $63.3 \%$ of cases and under ultrasound guidance in $36.7 \%$ of cases. Method of localization is widely variable among literature. Masroor et al. [10] had done WGL under mammography guidance in $53 \%$ of cases and under ultrasound guidance in $40 \%$ of the cases. On 
the other hand, de Roos et al. [11] had in their study ultrasound guided localization in $72.6 \%$ of patients, mammography guided localization in $26.5 \%$, and MRI guided localization in $0.9 \%$ of patients. Ultrasound guided localization had to be done if ultrasound could identify suspicious solid breast lesions while mammography guided localization had to be done for micro-calcifications or mammographically suspicious soft tissue densities [10]. In our study, $33.3 \%$ of patients were BIRADS III, $57.6 \%$ of them were BIRADS IV, and BIRADS V was found in $10 \%$ of patients. These results came in accordance with results of other studies. Raza et al. [12] reported rates of $38.4 \%, 56.6 \%$ and $5 \%$ for BIRADS III, IV, and V respectively. Mendez et al. [13] reported BIRADS III rate of $16.5 \%$, BIRADS IV rate of $80 \%$, and BIRADS V rate of $3.5 \%$. The mean tumor size in our study is 11.23 $\mathrm{mm}$. Histopathological examination revealed IDC in $56.7 \%$ of cases, DCIS in $30 \%$, and ILC in $13.3 \%$ of cases. These results are more or less consistent with the results from other studies [11] [14].

The main challenge in WGL excision biopsy is the proper excision of the non-palpable breast mass that provides local definitive treatment and proper histopathological diagnosis together with satisfactory cosmetic results for the patient [14]. This cosmetic result can be achieved by minimizing the excision of normal breast tissue around the non-palpable mass. Nevertheless, proper excision of safety margins around the malignant nonpalpable breast mass is mandatory as it saves the patient re-surgery that increases the cost, morbidity, and worsens the final cosmetic outcome [14]. The width of safety margins in patients undergoing breast conserving surgery is variable among literature. It ranges from "ink negative" to greater than $1 \mathrm{~cm}$ [15] [16]. In our study, we adopted $5 \mathrm{~mm}$ as the minimal accepted safety margins in the malignant cases. The mean safety margin of excision was $6.7 \mathrm{~mm}$. Margins of excision were involved $36.7 \%$ of cases who required re-excision. The rate of positive margins is widely variable. It ranges between $0 \%$ and $57.7 \%$ [17] [18]. Zgajner et al. [19] reported positive margin rate in 55\% of cases. Thind et al. [20] reported $40 \%$ involved margins rate. Ocal et al. [21] had 40\% incidence for re-excision in their patients. This variable rate of involved margins can be attributed to the procedure itself as it is technically demanding [11] [14] both radiologically and surgically specially the orientation of the surgeon for proper determination of the depth of the lesion that becomes more difficult in dense breast tissue. The relatively low incidence of positive margins in our study may be attributed to the older age of the patients included in the study as the mean age was 52.63 years.

Another limitation of the technique is the proper estimation of the proper size of the lesion by the radiologist specially in cases of extensive intra-ductal component, multifocal lesions, and invasive lobular carcinoma [11]. Also, the positive margins of excision can be attributed to some genetic biological differences and diffuse growth pattern in some non-palpable breast cancers [22]. Margins $1-5 \mathrm{~mm}$ are considered as close margins. The re-excision in these cases depends on many prognostic factors e.g. tumor size, grade, and receptor status [23]. In the literature, large tumor size, high pathological grade, and extensive intra-ductal component are significantly associated with positive resection margins [24] [25]. In our study, The larger tumor size and high pathological grade were associated with higher but statistically insignificant incidence of positive margins. This can be explained by the small sample size. So, we think that increasing the number of patients can lead to more significant results.

No operative or post-operative complications were reported in our study. In general, WGL biopsy is a safe surgical technique with minor complication rate that ranges between $0 \%$ and $1.3 \%$ [5] [10].

In conclusion, WGL biopsy is a reliable surgical technique that can provide surgical excision together with definitive diagnosis for patients presenting with suspicious non-palpable breast masses. WGL may be the only feasible technique when other localization methods cannot be performed e.g. U/S guided excision cannot be done in case of micro calcifications. WGL gives the patient good cosmetic result and low complications rate without exposure to radio-active substances that are used in the other localization techniques. However, the technique has its own limitations e.g. the learning curve for both the radiologist and surgeon, and the proper excision of adequate safety margins.

\section{References}

[1] Skinner, K.A., Silberman, H., Sposto, R., et al. (2001) Palpable Breast Cancers Are Inherently Different from NonPalpable Breast Cancers. Annals of Surgical Oncology, 8, 705-710. http://dx.doi.org/10.1007/s10434-001-0705-1

[2] Lovrics, P.J., Cornacci, S.D., Forrokhyar, F., et al. (2009) The Relationship between Surgical Factors and Margin Status after Breast Conservation Surgery for Early Stage Breast Cancer. The American Journal of Surgery, 197, 740-746. http://dx.doi.org/10.1016/j.amjsurg.2008.03.007

[3] Sajid, M.S., Paramplli, U., Haider, Z. and Bonomi, R. (2012) Comparison of Radio-Active Occult Lesion Localization (ROLL) and Wire Localization for Non-Palpable Breast Cancers: A Meta-Analysis. Journal of Surgical Oncology, 105, 
852-858. http://dx.doi.org/10.1002/jso.23016

[4] Symmonds, R.E. and Roberts, J.W. (1987) Management of Non-Palpable Breast Abnormalities. Annals of Surgery, 205, 520-528. http://dx.doi.org/10.1097/00000658-198705000-00010

[5] Lovrics, P.J., Cornacci, S.D., Vora, R., et al. (2011) Systematic Review of Radio-Guided Surgery for Non-Palpable Breast Cancer. European Journal of Surgical Oncology, 37, 388-397. http://dx.doi.org/10.1016/j.ejso.2011.01.018

[6] Acosta, J.A., Greenlee, J.A., Gubler, K.D., et al. (1995) Surgical Margins after Needle-Localization Breast Biopsy. The American Journal of Surgery, 170, 643-645. http://dx.doi.org/10.1016/S0002-9610(99)80033-6

[7] Postma, E.L., Witkamp, A.J., van den Bosch, M.A.A.J., et al. (2011) Localization of Non-Palpable Breast Lesions. pert Review of Anticancer Therapy, 1, 1295-1302. http://dx.doi.org/10.1586/era.11.116

[8] Frank, H.A., Hall, F.M. and Steer, M.L. (1976) Pre-Operative Localization of Non-Palpable Breast Lesions Demonstrated by Mammography. World Journal of Surgery, 295, 259-260.

[9] Muneer, A., Mieke, V.H. and Michael, D. (2013) Systematic Review of Radio-Guided versus Wire-Guided Localization in the Treatment of Non-Palpable Breast Cancers. Breast Cancer Research and Treatment, 140, 241-252. http://dx.doi.org/10.1007/s10549-013-2547-5

[10] Masroor, I., Afzal, S., Shafqat, G. and Rehman, H. (2012) Usefulness of Hook Wire Localization Biopsy under Imaging Guidance for Non-Palpable Breast Lesions Detected Radiologically. International Journal of Women's Health, $\mathbf{4}$, 445-449. http://dx.doi.org/10.2147/IJWH.S35280

[11] de Roos, M.A.J., Wevaart, W.N. and Ong, K.H. (2013) Should We Abandon Wire-Guided Localization for Nonpalpable Breast Cancer? A Plea for Wire-Guided Localization. Scandinavian Journal of Surgery, 102, 106-109. http://dx.doi.org/10.1177/1457496913482236

[12] Raza, S., Chikarmane, S.A., Neilsen, S.S., et al. (2008) BI-RADS 3, 4, and 5 Lesions: Value of US in ManagementFollow-Up and Outcome. Radiology, 248, 773-781. http://dx.doi.org/10.1148/radiol.2483071786

[13] Mendez, A., Cabanillas, F., Echenique, M., et al. (2004) Mammographic Features and Correlation with Biopsy Findings Using 11-Gauge Stereotactic Vaccum-Assisted Breast Biopsy (SVABB). Annals of Oncology, 15, 450-454. http://dx.doi.org/10.1093/annonc/mdh088

[14] Dogan, L., Gulcelik, M.A., Yuksel, M., et al. (2012) Wire-Guided Localization Biopsy to Determine Surgical Margin Status in Patients with Non-Palpable Suspicious Breast Lesions. Asian Pacific Journal of Cancer Prevention, 13, 49894992. http://dx.doi.org/10.7314/APJCP.2012.13.10.4989

[15] Singletary, S.E. (2002) Surgical Margins in Patients with Early-Stage Breast Cancer Treated with Breast Conservation Therapy. The American Journal of Surgery, 184, 383-393. http://dx.doi.org/10.1016/S0002-9610(02)01012-7

[16] Azu, M., Abrahamse, P., Katz, S.J., et al. (2010) What Is an Adequate Margin for Breast-Conserving Surgery? Surgeon Attitude and Correlates. Annals of Surgical Oncology, 17, 558-563. http://dx.doi.org/10.1245/s10434-009-0765-1

[17] Gray, R.J., Salud, C., Nguyen, K., et al. (2001) Randomized Prospective Evaluation of a Novel Technique for Biopsy or Lumpectomy of Non Palpable Breast Lesions, Radioactive Seed versus Wire Localization. Annals of Surgical Oncology, 8, 711-715. http://dx.doi.org/10.1007/s10434-001-0711-3

[18] Strnad, P., Rob, L., Halaska, M.G., et al. (2006) Radioguided Occult Lesion Localization in Combination with Detection of Sentinel Lymph Node in Non-Palpable Breast Cancer Tumors. European Journal of Gynaecological Oncology, 27, 236-238.

[19] Zgajner, J., Hocevar, M. and Frkovic-Grazio, S. (2004) Radioguided Occult Lesion Localization (ROLL) of the Nonpalpable Breast Lesions. Neoplasma, 51, 385-389.

[20] Thind, C.R., Desmond, S. and Harris, O. (2005) Radio-Guided Localization of Clinically Occult Breast Lesions (ROLL): A DGH Experience. Clinical Radiology, 60, 681-686. http://dx.doi.org/10.1016/j.crad.2004.12.004

[21] Ocal, K., Dag, A., Turkmenoglu, O., et al. (2011) Radioguided Occult Lesion Localization versus Wire-Guided Localization for Non-Palpable Breast Lesions: Randomized Controlled Trial. Clinics, 66, 1003-1007. http://dx.doi.org/10.1590/S1807-59322011000600014

[22] Gajdos, C., Tartter, P.I., Bleiweiss, I.J., et al. (2002) Mammographic Appearance of Nonpalpable Breast Cancer Reflects Pathologic Characteristics. Annals of Surgery, 235, 246-251. http://dx.doi.org/10.1097/00000658-200202000-00013

[23] Lovrics, P.J., Goldsmith, C.H., Hodgson, N., et al. (2011) A Multicentered Randomized Controlled Trial Comparing Radio-Guided Seed Localization to Standard Wire Localization for Nonpalpable Invasive and In Situ Breast Carcinomas. Annals of Surgical Oncology, 18, 3407-3414. http://dx.doi.org/10.1245/s10434-011-1699-y

[24] Sanchez, C., Brem, R.F., McSwain, A.P., et al. (2010) Factors Associated with Re-Excision in Patients with EarlyStage Breast Cancer Treated with Breast Conservation Therapy. The American Surgeon, 76, 331-334.

[25] Coopey, S., Smith, B.L., Hanson, S., et al. (2011) The Safety of Multiple Re-Excisions after Lumpectomy for Breast Cancer. Annals of Surgical Oncology, 18, 3797-3801. http://dx.doi.org/10.1245/s10434-011-1802-4 